\title{
Conhecimentos, atitudes e práticas dos enfermeiros na central de quimioterapia frente ao risco químico
}

\author{
Knowledge, attitudes and practices of nurses in central \\ chemical risk chemotherapy front
}

Giselle Gomes Borges ${ }^{1} \bullet$ Zenith Rosa Silvino² • Lia Cristina Galvão dos Santos ${ }^{3}$

\begin{abstract}
RESUMO
Durante o manuseio dos quimioterápicos antineoplásicos, é recomendado que o profissional utilize equipamentos de proteção individual (EPI), já que estes agentes oferecem efeitos indesejados e podem vir a constituir risco ocupacional. Objetivo: Apontar os Conhecimentos, Atitudes e Práticas (CAP) dos enfermeiros de duas Centrais de Quimioterapia (CQT) a respeito da exposição ao risco químico. Método: Trata-se de uma pesquisa descritiva com abordagem quantitativa, do tipo inquérito CAP. 0 estudo teve como amostra 26 enfermeiros. Foi utilizado para a coleta de dados um questionário autoadministrativo tipo Likert. Pesquisa aprovada pelo Comitê de Ética em Pesquisa sob n0 12361613.4.00005274, em 12/09/2014. Resultados: Constatou-se que o conhecimento constituído a respeito do risco químico foi adequado nas duas $\mathrm{CQT}$, contudo, as atitudes e práticas não foram coerentes com a exposição ao risco químico na CQT. Conclusões: Os profissionais que trabalham em CQT conhecem e consideram-se expostos ao risco químico. São necessárias intervenções para ampliar a adesão às medidas preventivas como o uso de EPI e subsídios com infraestrutura estratégica para a segurança do trabalhador.
\end{abstract}

Palavras-chave: Conhecimentos, atitudes e práticas em saúde; Riscos químicos; Quimioterapia; Biossegurança; Enfermagem oncológica.

\begin{abstract}
During handling of antineoplastic drugs it is recommended that professionals use personal protective equipment (PPE) as these agents provide unwanted effects and are liable to occupational risk. Objective: Aim Knowledge, Attitudes and Practices (KAP) of nurses in two Chemotherapy Centers (CQT) about exposure to chemical risk. Method: It is a descriptive research with a quantitative approach, the KAP. The study had as sample 26 nurses. It was used for data collection a questionnaire self-administered Likert. Research approved by the Research Ethics Committee under n0 12361613.4.00005274 on 12/09/2014. Results: It was found that knowledge made about chemical risk was adequate in both CQT, but the attitudes and practices were not consistent with exposure to chemical risk in the CQT. Conclusions: Professionals working in CQT know and consider themselves exposed to chemical risk. Interventions are needed to increase the adherence to preventive measures such as the use of PPE and subsidies to strategic infrastructure for worker safety.
\end{abstract}

Keywords: Knowledge, attitudes and health practices; Chemical risks; Chemotherapy; Biosafety; Oncology nursing.

${ }^{1}$ Enfermeira, Discente do Mestrado Profissional em Enfermagem Assistencial (MPEA/UFF). Líder da Central de Quimioterapia do Hospital do Câncer III/ INCA. Membro do Núcleo de Pesquisa Cidadania e Gerência na Enfermagem (NECIGEN).E-mail: ggomesborges@yahoo.com.br

${ }^{2}$ Doutora em Enfermagem. Professora Titular da EEAAF/UFF. Docente do Mestrado Profissional em Enfermagem Assistencial/UFF. Coordenadora do NECIGEN. E-mail: zenithrosa@terra.com.br

${ }^{3}$ Doutora em Enfermagem. Enfermeira do Hospital Federal de Bonsucesso/MS. E-mail: galvaoconsult@gmail.com.

Recorte da Dissertação de Mestrado intitulada "Manual de Boas Práticas sobre risco químico na Central de Quimioterapia do INCA a partir dos Conhecimentos, Atitudes e Práticas dos Enfermeiros" de autoria de Giselle Gomes Borges. Programa de Pós-Graduação Stricto Sensu - Mestrado Profissional em Enfermagem Assistencial da Universidade Federal Fluminense/UFF. Niterói, RJ. Data da defesa 29/10/2015

Os autores declaram não haver conflitos de interesse nem fontes de financiamento. 


\section{INTRODUÇÃO}

A quimioterapia antineoplásica (QA) começou a ser estudada e utilizada no final do século XIX, com a descoberta da solução de Fowler (arsenito de potássio) por Lissauer, em 1865, e da toxina de Coley (associação de toxinas bacterianas), em $1890^{1}$.

Os fármacos quimioterápicos podem vir a constituir risco que vai desde leves processos alérgicos até o câncer. Estes, em determinado nível, promovem, preservam e recuperam a saúde da população, mas, no ambiente hospitalar, podem provocar riscos à saúde do trabalhador de enfermagem, entre outros ${ }^{2}$. Como exemplos de grupos expostos podem ser citados os pacientes, os indivíduos que trabalham nas indústrias farmacêuticas, os trabalhadores que 0 preparam e o administram, os médicos e as enfermeiras que cuidam dos pacientes, o pessoal relacionado à limpeza, os familiares dos pacientes e os pesquisadores ${ }^{3}$.

Os riscos advindos da manipulação de quimioterápicos envolvem a inalação de aerossóis, o contato direto do medicamento com a pele, e mucosa e a ingestão de alimentos contaminados por resíduos. Há riscos, também, nas excretas dos pacientes submetidos aos tratamentos quimioterápicos, já que uma parcela dessas substâncias permanece inalterada ou sob a forma de metabólitos inativos capazes de prejudicar a saúde dos trabalhadores, acarretando-lhes mutagenicidade, infertilidade, aborto, malformações congênitas, genotoxicidade, câncer, irregularidades menstruais, perda do cabelo e sintomas imediatos como tontura, cefaleia, náuseas, vômitos, irritação da garganta e olhos, alterações de mucosa, bem como possíveis reações alérgicas e cutâneas ${ }^{4-6}$.

Ao descrever sobre estes fármacos, a literatura afirma que:"são substâncias capazes de produzir todos os tipos de lesão celular e os efeitos da exposição aos mesmos podem se manifestar imediata ou tardiamente [..]." . Portanto, durante a preparação desses medicamentos, é obrigatório que o profissional responsável utilize EPI, já que estas substâncias oferecem efeitos indesejados, exigindo, ainda, que sejam manipulados por profissionais capacitados e informados sobre o risco potencial a que estão expostos.

$\mathrm{O} E P I$ é todo dispositivo ou produto de uso individual destinado a proteger a saúde e a integridade física do trabalhador dos riscos suscetíveis a ameaças à segurança e à saúde no trabalho, incluindo luvas, aventais, protetores oculares, faciais e auriculares, protetores respiratórios e para os membros inferiores. É responsabilidade do empregador o fornecimento gratuito do EPI adequado ao risco e o treinamento dos trabalhadores quanto à forma correta de utilização e conservação. Os equipamentos devem ser aprovados por órgão competente do Ministério do Trabalho e Emprego (MTE) e receber um certificado de aprovação (CA $)^{7,8}$.

No âmbito das práticas laborais dos profissionais da saúde, as questões referentes a risco e/ou vulnerabilidade estão ainda mais presentes, uma vez que esses profissionais se expõem rotineiramente a múltiplos riscos. Na perspectiva da vulnerabilidade, aquilo que pode ocasionar um acidente por risco ocupacional é determinado por um conjunto de condições individuais e institucionais 9 . No caso dos trabalhadores que manipulam quimioterápicos, durante $\mathrm{o}$ preparo, administração e descarte, é significativo o risco a que estão expostos. Além disso, há trabalhadores que podem se expor indiretamente por conta da contaminação nas áreas de trabalho em caso de acidentes com derramamento de QA, reforçando-se que a contaminação ambiental deve ser igualmente considerada ${ }^{2,10}$.

A equipe de enfermagem merece atenção especial por estar entre as principais categorias sujeitas à exposição ocupacional. Possui o maior número de trabalhadores inseridos na área de saúde (técnicos e enfermeiros), executa uma diversidade de tarefas, sendo necessário, muitas vezes, o contato físico para a implementação de suas atividades; tem a responsabilidade por cerca de $60 \%$ das ações direcionadas ao cliente e à prestação de assistência ininterrupta durante as 24 horas do dia ${ }^{11}$. É uma equipe reconhecida por ser responsável pelo maior contingente da força de trabalho dos estabelecimentos hospitalares e é considerado o conjunto de trabalhadores que mais sofre com a inadequada condição de trabalho e com a insalubridade do ambiente laboral assistencial ${ }^{12}$.

Esses trabalhadores, frequentemente, estão expostos ao risco químico no dia a dia da assistência, gerado pelo manuseio de uma variedade de substâncias e também pela administração de medicamentos. A exposição ao risco químico está relacionada com a área de atuação do trabalhador, com o tipo de substância química e tempo de contato, além da concentração do mesmo. Constituindo um importante fator predisponente às doenças profissionais e uma ameaça à segurança em muitos ambientes laborais, como, por exemplo, em uma Central de Quimioterapia (CQT) ${ }^{13}$.

Esses desafios exigem cada vez mais trabalhadores qualificados e aperfeiçoados para lidar com as novas demandas do exercício profissional, direcionadas à realidade epidemiológica do nosso país, devido ao alto grau de complexidade no tratamento a que estão sujeitos os pacientes diagnosticados com câncer. As próprias instituições devem ter o compromisso de proporcionar oportunidades para a formação complementar necessária ao exercício profissional em área especializada, como é o caso da oncologia ${ }^{14}$.

\section{OBJETIVO}

Identificar os Conhecimentos, Atitudes e Práticas (CAP) dos enfermeiros de duas $\mathrm{CQT}$ a respeito da exposição ao risco químico.

\section{MÉTODO}

Trata-se de um estudo descritivo com abordagem quantitativa do tipo inquérito CAP que possui como 
objetivo a descrição das características de uma população, fenômeno ou experiência. Traduz os números em opiniões e informações para classificá-los e analisá-los ${ }^{15}$.

Os conceitos de CAP foram estabelecidos a partir de estudos similares conforme segue ${ }^{15}$ :

- Conhecimento - Significa recordar fatos específicos (dentro do sistema educacional do qual o indivíduo faz parte) ou a habilidade para aplicar fatos específicos para a resolução de problemas ou, ainda, emitir conceitos com a compreensão adquirida sobre determinado evento; dimensão intelectual.

- Atitude - É, essencialmente, ter opiniões. É, também, ter sentimentos, predisposições e crenças, relativamente constantes, dirigidos a um objetivo, pessoa ou situação. Relaciona-se ao domínio afetivo- dimensão emocional.

- Prática - É a tomada de decisão para executar a ação. Relaciona-se aos domínios psicomotor, afetivo e cognitivo - dimensão social.

0 inquérito CAP serve para ajudar no planejamento, implementação e avaliação do trabalho, recolhendo informações a respeito do que as pessoas sabem, o que pensam sobre ou a resposta à determinada situação. Podem identificar falhas de conhecimento, crenças culturais e padrões de comportamento que permitem a melhor compreensão da ação, assim como detecção de barreiras. Também identificam fatores que influenciam o comportamento não conforme das pessoas ${ }^{16}$.

Os guidelines de estudos CAP orientam a validação do instrumento de coleta de dados conduzida por um pré-teste em um pequeno grupo de representantes da população. O questionário deve ser aplicado em média a 10 pessoas, e, uma vez que este pequeno grupo tenha concluído o questionário, os resultados devem ser analisados. Esta análise deve validar o grau em que as questões foram devidamente compreendidas ou mal interpretadas ${ }^{17}$.

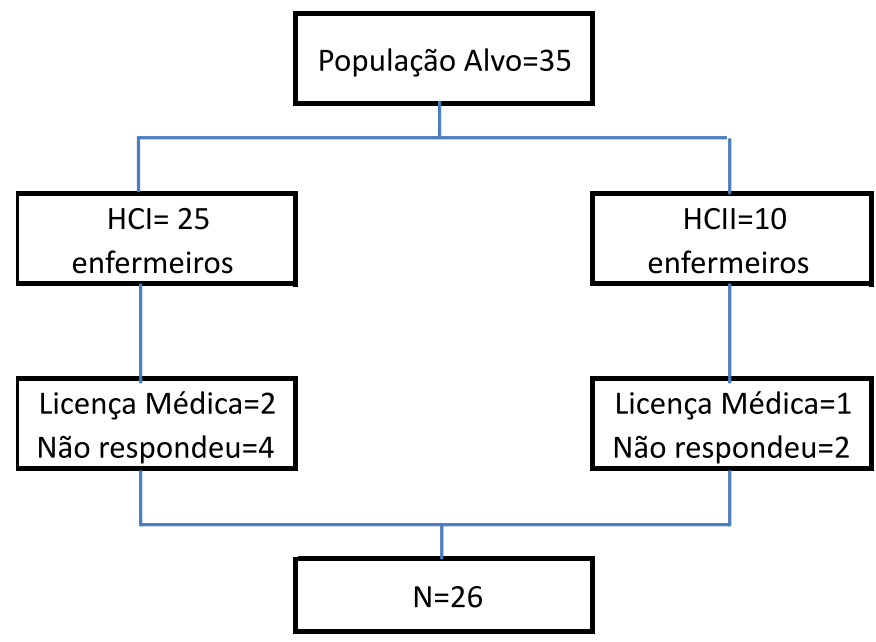

HCl: Hospital do Câncer I; HCII: Hospital do Câncer II.

Figura 1. Participantes da Pesquisa

Fonte: INCA, 2014
Os participantes da pesquisa foram 26 enfermeiros que exercem suas atividades laborais em duas CQT de um hospital público especializado e normatizado, localizado na cidade do Rio de Janeiro.

Como critério de inclusão, participaram da pesquisa os enfermeiros que atuam direto na assistência e que aceitaram participar de maneira voluntária após assinatura do Termo de Consentimento Livre e Esclarecido (TCLE). No critério de exclusão, estão enfermeiros licenciados, em período de férias e os residentes de enfermagem.

Para a execução da pesquisa o estudo foi enviado ao Comitê de Ética em Pesquisa (CEP) da instituição que o aprovou com o certificado de apresentação para apreciação ética (CAAE) $n^{0}$ 12361613.4.00005274, em 12/09/2014. $\mathrm{Na}$ coleta dos dados, utilizou-se um questionário autoadministrativo sem identificação, contendo perguntas em que se utiliza uma escala de resposta tipo Likert. A escala de Likert é considerada uma escala simples de resposta psicométrica, na qual cada participante atribui pontos de forma independente ${ }^{18}$.

\section{RESULTADOS}

Conforme demonstrado na tabela abaixo, frente aos resultados apresentados conclui-se que os profissionais avaliados conhecem a exposição ao risco químico em CQT.

Em torno de $46,2 \%$ concordam que os profissionais que não manuseiam quimioterápicos, mas trabalham em CQT, como profissionais da recepção e da limpeza, também estão sujeitos à exposição ao risco químico.

Um percentual de $96,2 \%$ dos participantes reconhece que o uso de EPI é essencial para o desenvolvimento das tarefas, e $92,3 \%$ concordam totalmente que o uso de EPI durante a administração dos quimioterápicos diminui a exposição do profissional ao risco químico. Por outro lado, $23 \%$ discordam que são indiferentes quanto ao uso de adornos, maquiagens e cosméticos como influência na segurança dos profissionais que manuseiam quimioterápicos.

Foi unânime entre os participantes que os resíduos químicos da CQT necessitam receber destinação específica. $E$ que o enfermeiro pode contribuir com a educação permanente dos profissionais como ferramenta de minimização do risco químico.

Evidenciado que $88,5 \%$ concordam totalmente que o uso de EPI é essencial para manusear excretas dos pacientes que receberam QA nas últimas $48 \mathrm{~h}$, enquanto $76,9 \%$ dos participantes concordam que as legislações que normatizam os serviços de quimioterapia abordam a segurança do profissional, que o serviço dispõe de um protocolo padrão para acidentes químicos e que os seus conhecimentos acerca do risco químico em uma CQT atendem às suas necessidades de trabalho.

\section{Atitudes dos enfermeiros sobre o risco químico}

As atitudes estão relacionadas com o que o enfermeiro acredita em relação ao risco químico. 
Tabela 1. Conhecimentos acerca dos ricos químicos pelos Enfermeiros da CQT.

\begin{tabular}{|c|c|c|c|c|c|c|c|c|c|c|}
\hline \multirow{2}{*}{ CONHECIMENTO } & \multicolumn{2}{|c|}{$\begin{array}{l}\text { discordo } \\
\text { totalmente }\end{array}$} & \multicolumn{2}{|c|}{$\begin{array}{c}\text { discordo } \\
\text { parcialmente }\end{array}$} & \multicolumn{2}{|c|}{ indiferente } & \multicolumn{2}{|c|}{$\begin{array}{c}\text { concordo } \\
\text { parcialmente }\end{array}$} & \multicolumn{2}{|c|}{$\begin{array}{l}\text { concordo } \\
\text { totalmente }\end{array}$} \\
\hline & $\mathbf{n}$ & $\%$ & n & $\%$ & $\mathbf{n}$ & $\%$ & $\mathbf{n}$ & $\%$ & $\mathbf{n}$ & $\%$ \\
\hline Risco químico & 0 & 0 & 3 & 11,5 & 0 & 0 & 0 & 0 & 23 & 88,5 \\
\hline Profissionais que não manuseiam QA & 3 & 11,5 & 1 & 3,8 & 2 & 7,7 & 8 & 30,8 & 12 & 46,2 \\
\hline $\begin{array}{l}\text { Uso indispensável de EPI na } \\
\text { administração }\end{array}$ & 1 & 3,8 & 0 & 0 & 0 & 0 & 0 & 0 & 25 & 96,2 \\
\hline EPI diminui a exposição & 0 & 0 & 0 & 0 & 0 & 0 & 2 & 7,7 & 24 & 92,3 \\
\hline Adornos influenciam na segurança & 1 & 3,8 & 4 & 15,4 & 1 & 3,8 & 8 & 30,8 & 12 & 46,2 \\
\hline Resíduos com destinação específica & 0 & 0 & 0 & 0 & 0 & 0 & 0 & 0 & 26 & 100,0 \\
\hline Manuseio de excretas e o uso de EPI & 0 & 0 & 0 & 0 & 2 & 7,7 & 1 & 3,8 & 23 & 88,5 \\
\hline Legislações abordam a segurança & 0 & 0 & 0 & 0 & 0 & 0 & 6 & 23,1 & 20 & 76,9 \\
\hline Protocolo padrão para acidentes & 1 & 3,8 & 0 & 0 & 0 & 0 & 5 & 19,2 & 20 & 76,9 \\
\hline $\begin{array}{l}\text { Educação como ferramenta para } \\
\text { minimizar o risco }\end{array}$ & 0 & 0 & 0 & 0 & 0 & 0 & 0 & 0 & 26 & 100,0 \\
\hline $\begin{array}{l}\text { Conhecimento atende as necessidades } \\
\text { de trabalho }\end{array}$ & 0 & 0 & 0 & 0 & 0 & 0 & 6 & 23,1 & 20 & 76,9 \\
\hline
\end{tabular}

Fonte: INCA, 2014.

Tabela 2. Atitudes/crenças dos enfermeiros da CQT relacionadas ao risco químico.

\begin{tabular}{|c|c|c|c|c|c|c|c|c|c|c|}
\hline \multirow{2}{*}{ ATITUDES } & \multicolumn{2}{|c|}{$\begin{array}{l}\text { discordo } \\
\text { totalmente }\end{array}$} & \multicolumn{2}{|c|}{$\begin{array}{c}\text { discordo } \\
\text { parcialmente }\end{array}$} & \multicolumn{2}{|c|}{ indiferente } & \multicolumn{2}{|c|}{$\begin{array}{l}\text { concordo } \\
\text { parcialmente }\end{array}$} & \multicolumn{2}{|c|}{$\begin{array}{l}\text { concordo } \\
\text { totalmente }\end{array}$} \\
\hline & $\mathbf{n}$ & $\%$ & $\mathbf{n}$ & $\%$ & $\mathbf{n}$ & $\%$ & $\mathbf{n}$ & $\%$ & $\mathbf{n}$ & $\%$ \\
\hline Adornos fixam partículas de QA & 1 & 3,8 & 3 & 11,5 & 1 & 3,8 & 9 & 34,6 & 12 & 46,2 \\
\hline EPI minimiza a exposição & 0 & 0 & 0 & 0 & 0 & 0 & 2 & 7,7 & 24 & 92,3 \\
\hline EPI utilizado durante toda a jornada & 0 & 0 & 0 & 0 & 0 & 0 & 2 & 7,7 & 24 & 92,3 \\
\hline $\begin{array}{l}\text { Quimioterápicos podem trazer prejuízos a } \\
\text { saúde }\end{array}$ & 1 & 3,8 & 0 & 0 & 0 & 0 & 5 & 19,2 & 20 & 76,9 \\
\hline $\begin{array}{l}\text { Luvas e higienizar as mãos atitudes } \\
\text { adequadas }\end{array}$ & 0 & 0 & 0 & 0 & 0 & 0 & 2 & 7,7 & 24 & 92,3 \\
\hline $\begin{array}{l}\text { Luva e álcool gel substitui a higienização } \\
\text { das mãos quando não há sujidade }\end{array}$ & 3 & 11,5 & 3 & 11,5 & 2 & 7,7 & 9 & 34,6 & 9 & 34,6 \\
\hline Questiona a chefia quando não há EPI & 1 & 3,8 & 0 & 0 & 0 & 0 & 0 & 0 & 25 & 96,2 \\
\hline $\begin{array}{l}\text { Exemplos do trabalho para atividade de } \\
\text { educação }\end{array}$ & 0 & 0 & 0 & 0 & 0 & 0 & 1 & 3,8 & 25 & 96,2 \\
\hline $\begin{array}{l}\text { Orientações do protocolo em caso de } \\
\text { acidente protege o profissional }\end{array}$ & 0 & 0 & 0 & 0 & 0 & 0 & 6 & 23,1 & 20 & 76,9 \\
\hline
\end{tabular}

Fonte: INCA, 2014.

A fixação de partículas (aerossóis) de QA quando utilizase adornos, maquiagens e cosméticos foi reconhecida por $46,2 \%$ dos participantes que concordam totalmente com a afirmativa.

Em relação ao uso de EPI 92,3\% concordam que o uso de EPI minimiza a exposição ao risco químico sendo a importante seu uso durante toda a jornada de trabalho em que são manuseados QA. Esse mesmo percentual considera atitudes adequadas à troca de luvas e a higienização das mãos ao atender os pacientes. Já em relação a não sujidade visível das mãos, 34,6\% acreditam que o uso de álcool gel e a trocas das luvas são suficientes, não sendo necessária lavagem. Acredita-se que exista uma predisposição para lavar as mãos quando estas estão visivelmente sujas. A tabela a seguir demonstra a relação das atitudes e crenças dos entrevistados acerca do risco químico.

No que diz respeito ao prejuízo à saúde, $76,9 \%$ acreditam nesta assertiva. E em relação aos acidentes químicos, 76,9\% acreditam que as orientações do protocolo padrão podem proteger o profissional.

Entre os participantes, $96,2 \%$ consideram adequado questionar a chefia quanto à ausência de EPI e que os 
Tabela 3. Práticas dos Enfermeiros realizadas na CQT frente ao risco químico

\begin{tabular}{|c|c|c|c|c|c|c|c|c|c|c|}
\hline \multirow{2}{*}{ PRÁTICAS } & \multicolumn{2}{|c|}{$\begin{array}{l}\text { discordo } \\
\text { totalmente }\end{array}$} & \multicolumn{2}{|c|}{$\begin{array}{l}\text { discordo } \\
\text { parcialmente }\end{array}$} & \multicolumn{2}{|c|}{ indiferente } & \multicolumn{2}{|c|}{$\begin{array}{c}\text { concordo } \\
\text { parcialmente }\end{array}$} & \multicolumn{2}{|c|}{$\begin{array}{l}\text { concordo } \\
\text { totalmente }\end{array}$} \\
\hline & $\mathbf{n}$ & $\%$ & $\mathbf{n}$ & $\%$ & n & $\%$ & $\mathbf{n}$ & $\%$ & $\mathbf{n}$ & $\%$ \\
\hline EPI são utilizados & 1 & 3,8 & 0 & 0,0 & 1 & 3,8 & 7 & 26,9 & 17 & 65,4 \\
\hline Adornos removidos & 1 & 3,8 & 3 & 11,5 & 5 & 19,2 & 9 & 34,6 & 8 & 30,8 \\
\hline $\begin{array}{l}\text { Higienização das mãos antes e após atender } \\
\text { os pacientes }\end{array}$ & 0 & 0,0 & 0 & 0,0 & 1 & 3,8 & 3 & 11,5 & 22 & 84,6 \\
\hline $\begin{array}{l}\text { Ingesta de líquidos e alimentos em local } \\
\text { apropriado }\end{array}$ & 1 & 3,8 & 0 & 0,0 & 1 & 3,8 & 8 & 30,8 & 16 & 61,5 \\
\hline Acidente quando ocorre inicia-se o protocolo & 0 & 0,0 & 0 & 0,0 & 0 & 0,0 & 2 & 7,7 & 24 & 92,3 \\
\hline $\begin{array}{l}\text { Elabora o registro do acidente e notifica aos } \\
\text { responsáveis }\end{array}$ & 0 & 0,0 & 0 & 0,0 & 1 & 3,8 & 2 & 7,7 & 23 & 88,5 \\
\hline EPI confortável & 2 & 7,7 & 2 & 7,7 & 3 & 11,5 & 13 & 50,0 & 6 & 23,1 \\
\hline Questiona ausência de EPI a chefia & 0 & 0,0 & 1 & 3,8 & 2 & 7,7 & 7 & 26,9 & 16 & 61,5 \\
\hline Reunião como atividade de educação & 11 & 42,3 & 3 & 11,5 & 2 & 7,7 & 8 & 30,8 & 2 & 7,7 \\
\hline
\end{tabular}

Fonte: INCA, 2014.

exemplos da prática no trabalho podem ser utilizados para a educação vislumbrando a prevenção de riscos.

\section{Práticas dos enfermeiros sobre o risco químico}

Conforme demonstrado na tabela abaixo, os resultados em relação às práticas não tiveram a totalidade de correlação com o conhecimento.

Apesar de $96,2 \%$ dos participantes concordarem totalmente com a afirmativa de que o uso de EPI é indispensável para administração dos QA, na prática, $65,4 \%$ afirmam utilizá-los nos momentos de possível exposição química, enquanto apenas $30,8 \%$ retiram seus adornos ao iniciar a jornada de trabalho.

Em relação à prática de higienização das mãos, 84,6\% afirmam realizá-la previamente e posteriormente ao atendimento dos pacientes.

Importante citar que, diante de um acidente químico com derramamento de QA, apenas $61,5 \%$ afirmam iniciar imediatamente o protocolo padrão. Este fato não ocorre integralmente com a equipe, o que deveria ser esperado e preconizado. Porém, $88,5 \%$ elaboram o registro do acidente e notificam aos setores responsáveis.

A metade dos participantes considera confortável o uso dos EPI, embora $61,5 \%$ afirmem questionar à chefia quando ocorre a indisponibilidade dos equipamentos de proteção no serviço.

As reuniões em serviço para discussão de atividades de educação não vêm ocorrendo mensalmente com o intuito da melhoria do serviço.

É notório que o inquérito CAP considerado sequencial não ocorreu na afirmativa a respeito da higienização das mãos em relação às atitudes e práticas. Visto que, na questão anterior, foi dito que a higienização das mãos não foi considerada primordial e poderia ser realizada a troca de luvas ou higienização com álcool gel. Em CQT pela obrigatoriedade do uso da luva como EPI faz-se necessário lavar as mãos após a troca. Nesse caso a higienização apenas com álcool não seria suficiente, pois permaneceriam resíduos do talco.

As atividades de educação também deveriam ser inseridas nas reuniões de serviço com a finalidade de sempre melhorar a prática com a aquisição e troca de conhecimentos.

\section{ANÁLISE E DISCUSSÃO DOS DADOS}

A partir do inquérito CAP do tema proposto, foi possível identificar as ideias centrais do estudo que são o conhecimento da exposição ao risco químico na CQT, a importância do uso do EPI e a necessidade de trabalhos de educação com a proposta de atualização do tema em estudo.

Acredita-se que a questão da exposição ao risco químico é complexa e não deve ficar restrita a normas e leis, mas abranger a discussão sobre a prática profissional da enfermagem. Recentemente, os serviços de saúde do trabalhador vêm adotando como modelo o conceito de hierarquia de controle usado na higiene do trabalho para priorizar as intervenções de prevenção da exposição ao risco. Essa estratégia envolve fases de análise, entre as quais a primeira opção seria o afastamento ou eliminação do problema, seguida pelo degrau de redução do risco em níveis aceitáveis, ações de controle do risco por meio de projetos de engenharia, ações de administração do risco e, por fim, a obrigatoriedade do uso de EPI. Ou seja, somente quando essas estratégias não estão disponíveis ou não fornecem proteção completa, é que o foco deve ser na implementação das mudanças na prática de trabalho e no uso do $\mathrm{EPI}^{18}$. 


\section{Os conhecimentos, atitudes e práticas dos enfermeiros a respeito do risco químico}

Conhecimentos dos enfermeiros relacionados ao risco químico

Em relação aos conhecimentos da exposição ao risco químico em uma CQT, há concordância que trabalhar em CQT ocorre e impõe o risco, inclusive, para os profissionais que não manuseiam $\mathrm{QA}$, como os administrativos e auxiliares de serviços gerais.

O conhecimento acerca da biossegurança no ambiente da quimioterapia enfatiza aspectos relacionados ao ambiente e ao uso de EPI. Essa abordagem, embora importante, não deveria ser o único foco, uma vez que nos deparamos, na prática, principalmente com a baixa adesão ao uso dos EPI, resultando em possíveis danos à saúde do trabalhador ${ }^{19}$.

$\mathrm{O}$ trabalhador destes serviços tem noção dos riscos e dos possíveis danos existentes no ambiente de trabalho e, na sua percepção, estes riscos estão intimamente ligados ao aparecimento de sintomas, doenças e acidentes. Considera-se isto bastante positivo, pois pode ser um ponto de partida para elaboração de programas de treinamento e discussões sistemáticas com todos os seguimentos (instituição, sindicatos, trabalhadores, clientela e escola) ${ }^{20}$.

Como exemplos de grupos expostos podem ser citados os pacientes, os indivíduos que trabalham na indústria farmacêutica, os trabalhadores que preparam e administram os QA (farmacêuticos, enfermeiros e técnicos de enfermagem), os médicos o pessoal relacionado à limpeza, os familiares e os pesquisadores ${ }^{3}$.

A simples exposição a um agente químico pode provocar um determinado efeito no profissional, porém, se diminuirmos a exposição com o uso dos EPI, os efeitos e toxicidades serão de menor intensidade.

Os riscos advindos do manuseio de QA envolvem a inalação de aerossóis, o contato direto com a pele e mucosas e a ingestão de alimentos contaminados por resíduos do mesmo. 0 risco pode advir também das excretas dos pacientes em uso de $\mathrm{QA}^{4-6}$.

Sendo importante que não use adornos como maquiagens e cosméticos, pois podem influenciar na segurança do profissional com a possibilidade de fixação de partículas (aerossóis) de QA. A exposição ocupacional, muitas vezes, é subestimada pelos profissionais da enfermagem².

Têm-se como ações indispensáveis em relação ao gerenciamento da segurança dos profissionais: manter fichas de registro para acompanhamento de acidentes, estabelecer avaliação clínica e laboratorial com a finalidade de detectar precocemente alterações que possam estar relacionadas ao manuseio de QA e avaliar as medidas de proteção empregadas 4 .

Atitudes e crenças dos enfermeiros relacionados ao risco químico

De acordo com os achados foi possível perceber que os participantes acreditam que trabalhar em CQT impõe a situação de exposição ao risco químico.
O trabalhador tem noções do risco e dos possíveis danos, embora, na sua crença, esses riscos estão intimamente ligados ao aparecimento de sintomas e doenças relacionadas à exposição ${ }^{20}$.

Os profissionais de enfermagem assinalam as substâncias químicas como risco, mas, muitas vezes, desconhecem de que forma essas substâncias apresentamse no ambiente de trabalho ao não visualizarem as névoas. Essa forma é uma das mais frequentes no serviço de quimioterapia. Por ser invisível e por não ser reconhecida como risco químico pelos profissionais, a utilização dos equipamentos de proteção individual e coletiva pode ser negligenciada ${ }^{21}$.

É vetado iniciar as atividades relacionadas ao manuseio de QA na falta de EPI. A Occupational Safety and Health Administration (OSHA) estabelece o uso de luvas de látex ou polipropileno, descartáveis e sem talco; aventais descartáveis, com mangas longas, fechados na parte frontal, punhos com elásticos; máscaras com proteção de carvão ativado e óculos de proteção ${ }^{1}$.

É importante ressaltar que, de acordo com as Normas da Comissão de Controle de Infecção Hospitalar do Instituto Nacional de Câncer (INCA), o profissional deverá realizar a higienização das mãos antes e após manusear pacientes. 0 uso de luvas e álcool gel são importantes somente após a higienização, no caso das CQT. Considerando que em CQT a luva é utilizada durante toda a jornada de trabalho e a lavagem das mãos deve ser realizada antes e pós o uso das mesmas.

\section{Práticas dos enfermeiros relacionados ao risco químico}

Com relação às atitudes de proteção aos riscos observados, verificou-se que estas não são seguidas regularmente pelos participantes da pesquisa, embora eles afirmem adesão e conhecimento quanto às normas. Isto leva a inferir que há uma lacuna entre o conhecimento citado e a ação, o que, na opinião das autoras, poderá ser suprido por um processo de educação transformadora.

$A$ adesão aos EPI ocorre em momentos de possível exposição química, porém os adornos não são removidos por todos os profissionais no início das atividades laborais, apesar de conhecerem e acreditarem na ocorrência de fixação de partículas (aerossóis) de QA.

Alguns trabalhadores apresentam como justificativa para a não utilização dos EPI, a sua inexistência, o que é bastante preocupante, uma vez que as instituições deveriam, obrigatoriamente, fornecê-los quando necessário, em perfeito estado de conservação e funcionamento ${ }^{1}$.

A prática de higienização das mãos vem em controvérsia com a atitude. Apesar de afirmarem que realizam o procedimento antes e depois do atendimento do paciente. Existe a crença de que o uso de luvas e álcool gel quando não há sujidade substitui a higienização. De acordo com a OSHA ${ }^{1}$ há a recomendação de lavar as mãos rigorosamente antes e após a colocação das luvas. 
Parece pertinente sugerir as CQT que elaborem e promovam cursos de capacitação e recapacitação para os trabalhadores. Incluindo programas de monitorização ambiental, biológica, de vigilância à saúde e de gerenciamento dos resíduos sólidos produzidos ${ }^{3}$.

\section{CONCLUSÕES}

A pesquisa realizada com enfermeiros em duas Centrais de Quimioterapia de um hospital público especializado no município do Rio de Janeiro, cujo objetivo foi apontar os Conhecimentos, Atitudes e Práticas dos Enfermeiros em duas CQT a respeito do risco químico nos permitiu concluir que os profissionais que trabalham em CQT conhecem e consideram-se expostos ao risco químico, contudo, as atitudes e práticas não são coerentes.

Entende-se que a abordagem aos profissionais a partir do inquérito CAP possibilita a discussão no coletivo, não só do conhecimento desse profissional quanto aos riscos a que está submetido, mas também e principalmente quanto aos aspectos relacionados às suas atitudes e práticas diante do mesmo. Nesse sentido, novos estudos devem utilizar essa ferramenta como estratégia de gestão do risco químico na CQT.

As contribuições deste estudo vão além da produção do conhecimento a respeito da existência do risco químico a que os profissionais estão expostos em CQT e poderão servir de guia e subsidiar em práticas corretas e uniformes nesse ambiente de trabalho.

A lógica do modelo CAP pressupõe que comportamentos em saúde se prendem a um processo sequencial:a aquisição de um conhecimento correto leva a uma atitude favorável que, por sua vez, pode conduzir a práticas saudáveis. Com isso, espera-se que o conhecimento adequado seja uma das características que favoreça mudanças positivas de comportamento.

\section{REFERÊNCIAS}

1. Bonassa EMA, Gato, MIR. Terapêutica Oncológica para Enfermeiros e Farmacêuticos. Rio de Janeiro: Atheneu; 2012.

2. Costa TF, Felli VEA. Exposição dos trabalhadores de enfermagem às cargas químicas em um hospital público universitário da cidade de São Paulo. Rev. Latino-Am. Enfermagem. 2005; 13(4). Disponível em http://www.scielo. br/pdf/rlae/v13n4/v13n4a07.pdf. Acessado em: 09/08/2014.

3. Martins I, Rosa HVD. Considerações Toxicológicas da Exposição Ocupacional dos Fármacos Antineoplásicos. Rev. Bras. Med. Trab. 2004; 2(2): 118-125. Disponível em http:// www.bvsde.paho.org/bvsacd/cd49/rbmt05.pdf . Acessado em: 10/08/2014.

4. Rocha FL, Marziale MHP, Robazzi MLCC. Perigos potenciais a que estão expostos os trabalhadores de enfermagem na manipulação de quimioterápicos antineoplásicos: conhecêlos para preveni-los. Rev. Latino-Am. Enfermagem. 2004; 12(3): 511-517. Disponível em http://www.scielo.br/pdf/rlae/ v12n3/v12n3a09.pdf. Acessado em: 03/08/2014.
5. Mahboob M, Rahman MF, Rekhadevi PV, Sailaja N, Balasubramanyam A, Prabhakar PV et al. Monitoring of oxidative stress in nurses occupationally exposed to antineoplastic drugs. Toxicology Internacional. 2012; 19(1): 20-24. Disponível em http://www.pubmed.gov . Acessado em $15 / 09 / 2014$.

6. Xelegati R, Robazzi MLCC, Marziale MHP, Haas VJ. Riscos ocupacionais químicos identificados por enfermeiros que trabalham em ambiente hospitalar. Rev. Latino-Am. Enfermagem. 2006; 14(3). Disponível em http://www. scielo.br/pdf/rlae/v14n2/pt_v14n2a10.pdf. Acessado em: 18/08/2014.

7. Bulhões I. Riscos do trabalho de enfermagem. Rio de Janeiro: Folha Carioca; 1998.

8. Ministério do Trabalho e Emprego (Brasil). Portaria $n^{\circ} 485$, de 11 de Novembro de 2005. Aprova a Norma Regulamentadora n 32 (Segurança e Saúde no Trabalho em Estabelecimentos de Saúde). Brasília, DF: Diário Oficial da União, 16 novembro de 2005.

9. Santos J, Vieira M, Assuiti LFC, Gomes D, Meirelles BHS, Santos SMA. Risco e vulnerabilidade nas práticas dos profissionais de saúde. Rev Gaúcha Enferm. 2012; 33(2): 205-212. Disponível em: http://seer.ufrgs.br/RevistaGauchadeEnfermagem/article/ viewFile/19981/19512. Acessado em 20/12/2014.

10. Maia PG. A atividade da equipe de enfermagem e os riscos relacionados à exposição a quimioterápicos antineoplásicos no setor de oncologia de um hospital público do estado do Rio de Janeiro. 144p. Dissertação (Mestrado em Ciências na Área de Saúde Pública). Rio de Janeiro: Fundação Osvaldo Cruz/FIOCRUZ; 2009.

11. Nichiata LYI, Bertolozzi MR, Takahashi RF, Fracolli LA . A utilização do conceito vulnerabilidade pela enfermagem. Rev Latino-Am Enfermagem. 2008; 16(5): 923-928.

12. Costa FM, Vieira MA, Sena RR. Absenteísmo relacionado à doenças entre membros da equipe de enfermagem de um hospital escola. Rev Bras Enferm. 2009.62(1): 38-44, 2009. Disponível em http://www.scielo.br/pdf/reben/v62n1/06.pdf . Acessado em: 17/08/2014.

13. Castro MR, Farias SNP. A produção científica sobre riscos ocupacionais a que estão expostos os trabalhadores de enfermagem. Esc Anna Nery Rev Enferm. 2008; 12(2): 364369. Disponível em: http://www.scielo.br/pdf/ean/v12n2/ v12n2a26.pdf. Acessado em: 10/08/2014.

14. Amador DD, Gomes IP, Coutinho SED, Costa TNA, Collet N. Concepção dos enfermeiros acerca da capacitação no cuidado à criança com câncer. Texto Contexto Enfer. 2011; 20(1): 94101. Disponível em: http://www.scielo.br/pdf/tce/v20n1/11. pdf. Acessado em: 28/04/2014.

15. Marinho LAB, Costa-Gurgel MS, Cecatti JG, Osis MJD. Conhecimento, atitude e prática do autoexame das mamas em centros de saúde. Rev Saúde Pública. 2003; 37(5): 576-582. Disponível em: http://www.scielo.br/pdf/rsp/v37n5/17471. pdf . Acessado em: 16/06/2014.

16. WHO. World Health Organization. Advocacy, communication and social mobilization for TB control. A guide developing knowledge, attitude and practice surveys. Switzerland, 2008.

17. Kaliyaperumal K, Expert IEC. Guideline for Conducting a Knowledge, Attitude and Practice (KAP) Study. Community Ophthalmology: Diabetic Retinopathy Project.2004; 4 (1). 
18. Silva UF, Tanaka OY. Técnica de Delphi: identificando as competências gerais do médico e do enfermeiro que atuam em atenção primária de saúde. Rev Esc Enferm USP. [Internet] 1999 set [citado 2015 nov 21];33(3):207-16. Disponível em: http://www.scielo.br/pdf/reeusp/v33n3/v33n3a01.pdf

19. Ministério do Trabalho e Emprego (Brasil). Manual de implementação : programa de prevenção de acidentes com materiais perfurocortantes em serviços de saúde / Cristiane Rapparini ; Érica Lui Reinhardt. - São Paulo : Fundacentro, 2010.161 p.

20. Borges GG, Nunes LMP, Santos LCG, Silvino ZR. Biossegurança na Central de Quimioterapia: o Enfermeiro frente ao Risco Químico. Revista Brasileira de Cancerologia 2014; 60(3): 247250.

21. Ferreira ARA. Condições de trabalho e riscos para a saúde dos trabalhadores que preparam e/ou administram quimioterápicos em hospitais do município do rio de Janeiro [dissertação]. Rio de Janeiro: Universidade do Estado do Rio de Janeiro; 2000.

22. Santos CC. Percepção dos profissionais de enfermagem de um serviço de quimioterapia sobre os riscos ocupacionais no trabalho [dissertação]. Rio de Janeiro: Universidade do Estado do Rio de Janeiro; 2004. 